\title{
Os Candomblés Angola - Ngoma e as sonoridades sagradas de matriz Banto no Brasil
}

\author{
Luna Borges Berruezo ${ }^{1}$
}

\section{Resumo}

Este trabalho pretende apresentar o levantamento de referências bibliográficas com o intuito de produzir revisão bibliográfica sobre o Candomblé Angola - daquilo que já foi registrado e observado no Brasil - e suas práticas ritualísticas correspondentes aos cultos de origem banto, e em especial referente aos terreiros denominados angola presentes na região sudeste brasileira. Desta forma, o presente trabalho pretende dialogar com as referências bibliográficas existentes para embasar a experiência etnográfica em campo, assim como propiciar a noção de distinção entre as demais nações de candomblé.

A pesquisa etnográfica fundamenta-se na observação dos rituais públicos e do contato com os membros e sacerdotes de nação angola da Casa de Candomblé Angola Redandá ou Reino de Dandalunda, localizada na cidade de Cipó Guaçú, em São Paulo. O estudo está baseado na trajetória do responsável pela casa nomeado ritualisticamente como Tateto Mona Guiamazy - mais conhecido como Pai Guiamazy, que de acordo com a linhagem é filho de Gitadê e neto de Tata Londirá (o conhecido Joãozinho da Goméia) de reconhecida importância para a prática ritual do candomblé na Bahia e posteriormente pela expansão na região Sudeste - com o objetivo de reconhecer a trajetória ancestral do terreiro e a fundamentação da memória e da narrativa oral como formas de transmissão das sabedorias sagradas.

"O ingoma é a comunicação com os Inkisses. Ele, homem, faz o som e emite o som. O ingoma para o Angola, como para qualquer nação, é tudo." TATA

\footnotetext{
1 Aluna de Graduação no Departamento de Ciências Sociais, da Universidade Federal de São Paulo - UNIFESP. lu.lunaborges@ gmail.com - tel. (11) 9-9402-9453

Orientador: Prof. Doutor José Carlos Gomes da Silva

Co-orientação: Profa. Doutora Patrícia Teixeira Santos
} 
O ingoma ou ngoma(tambor) nas nações de candomblé tem fundamental importância ritualística e sagrada aos cultos, onde é através das sonoridades específicas de cada linhagem e nação que são relacionadas as correspondências vibratórias e o axé equivalente de cada terreiro. Nestas sonoridades sagradas estão presentes os fundamentos de suas casas, a sabedoria e conhecimento das práticas sagradas, como o xirê. O iniciado nas práticas ritualísticas de toque tem conhecimento das simbologias, das forças da natureza e/ou da linhagem dos ancestrais, e do tempo sagrado. Tendo como referência a figura do kisikarangombe (tocador, função conhecida como ogã nas demais matrizes religiosas) e kambandu (tocador assentado/confirmado na função, conhecido na nação Ketu como Alabê), é considerado um kiandú(cargo) simbolicamente importante para a tradição e para a transmissão oral dos fundamentos e saberes sagrados, que por meio da sonoridade ritualística (ritmo, canto das cantigas sagradas e toque do ngoma) propiciam o transe aos iniciados para o contato com os inkisses. No âmbito dos inkisses, na Casa de Candomblé Angola Redandá são cultuados: Ungira, Roxi Mukumbi, Lambaranguanje, Katendê, Zazy Luango, Kingongo, Angoro, Gongonbila, Kavunge (Tempo), Vunge, Dandalunda, Matamba, Gangazumbá, Kaya, Lembarenganga, Lembafuranga e Zambi Apongo.

O toque dos tambores - mais especificamente os atabaques - da nação angola são tocados com as mãos e compreendem os toques de Kabula, Congo-de-ouro, Barra-Vento e Ijexá, e suas características peculiares de timbre sonoro configuram a tríade: ngoma tixinda (conhecido também como rum, atabaque com sonoridade de timbre grave e com manulação base tendo liberdade de preenchimento de notas preponderantemente graves, geralmente é associado ao maior tambor), ngoma mukundu (rumpi, atabaque com sonoridade de timbre intermediário e com manulação base,geralmente está associado ao tambor de tamanho médio) e ngoma kasumbi (lé, atabaque com sonoridade de timbre agudo, manulação preenchida com notas preponderantemente agudas, geralmente está associado ao tambor de tamanho menor) - juntamente com os demais instrumentos utilizados ritualisticamente nos terreiros de nação angola, 
como o agogô que está associado ao canto e é tocado nas aberturas dos toques - onde posteriormente são tocados os ingomas - prosseguindo até o encerramento do ponto cantado, sempre associado dança ritual, canto e transe.

O conhecimento dos fundamentos, a compreensão das forças da Natureza, dos cultos aos ancestrais africanos, assim como o reconhecimento da língua banto e dos dialetos quimbundo e quicongo fazem-se necessários, a medida que o estudo das sonoridades de matriz africana implica também o contato e conhecimento dos pontos cantados de tradição banto no que refere às suas narrativas e simbologias culturais. Estas configuram as mitologias, os elos de ancestralidade, o culto e a cosmologia à Natureza como também remetem a contextos geográficos e territoriais do continente Africano.

A eminente produção de estudos e pesquisas etnográficas sobre o candomblé teve sua referência nos cultos iorubás realizados nas terras brasileiras, baseados por vezes na construção de noções de maior "pureza" de uma africanidade elemental, de hierarquias e organização particulares. Em especial, os ritos jeje-nagô de culto aos orixás—com origem nas diferentes regiões africanas de Ketu, Ijexá e Efã - estes de predominância na Bahia, e também aos ritos de origem fon conhecidos como tambor de mina - de culto aos voduns.

O reconhecimento da importância dos cultos de matriz de nação angola não esteve presente historicamente nas produções etnográficas - considerando a massiva presença em terras brasileiras dos povos de origem banto durante todo o processo diaspório de migração forçada que data do século XV ao XIX - destes terreiros, fundados na Bahia em períodos que datam do século XIX e XX, respectivamente registrados como o Tata Maquende (registrado em 1806, regente Oxalá), o Terreiro Bate Folha (1916, regente Iansã) e Unzo Tumba Junçara (1919, regente Tempo).

Considerando a ausência de referências etnográficas escritas a respeito dos cultos da nação angola, Reginaldo Prandi menciona "preconceituosamente, o candomblé angola tem sido considerado um rito menor, e dele pouco se estudou. (...) O candomblé angola legitimou desde cedo o culto dos 
caboclos brasileiros, que além de constituir como rito independente, foi também incorporado lá pelos anos 30 e 40 por casas nagôs(...)”.

Nesta perspectiva, Prandi em seu estudo sobre os candomblés de São Paulo faz referência às demais nações de terreiro, relacionando os diferentes objetos de estudo nas produções etnográficas existentes "Em consequência disso, o candomblé nagô pode contar, além do prestígio, com muitas fontes escritas brasileiras, além de uma etnografia produzida sobre o culto dos orixás da Nigéria e do Benin, que legitimaram esta tradição (...)", e segue "Nada semelhante existe para o candomblé de angola, a não ser o ensino do quicongo oferecido pela Universidade Federal da Bahia(...)".

Posteriormente, relata o discurso de Esmeraldo Emérito de Santana, representante da nação angola no Encontro de Nações de Candomblé, realizado em Salvador/Bahia em 1981 “Aqui faço um apelo, já que existe um centro de estudos, para que pesquisem o angola. Não há livros sobre o angola. E tem mais terreiros de angola na Bahia do que de queto, de jeje, de qualquer nação".

A compreensão da cosmologia banto, mantida por meio da ritualística da Casa de Candomblé de Angola Redandá, em sua dimensão sonora se apresenta relacionada aos processos de transmissão das sabedorias sagradas a todos(as) iniciados(as) da casa. A função de tocadores é designada pelos jogos de adivinhação através das manifestações dos inkisses relacionado ao destino de cada pessoa. Por meio da música ritual é guiada a maior parte dos atos rituais do candomblé, a música ritual estabelece a conexão entre os inkisses e os iniciados através do transe, cada sonoridade possui seu momento específico para ser transmitida, o som comunica e transmite, e os tocadores são aqueles incumbidos de fazer ecoar a comunicação do ngoma sagrado.

Nesta pesquisa direciono o estudo etnográfico ao papel ritual da música no Candomblé Angola para delinear como problema de pesquisa a compreensão dos elementos instrumentais e funções ritualísticas relacionadas aos processos de transmissão das sabedorias aos iniciados(as), considerando as correspondências simbólicas das narrativas musicais de língua banto para apontar sobre alguns aspectos destas sonoridades em relação à dimensão de ancestralidade no candomblé de nação angola. Com 
o intuito de analisar a produção dos estudos direcionados ao candomblé de nação angola, a revisão bibliográfica embasa a pesquisa do percurso histórico desta matriz banto, contribuindo com as referências sobre a temática e a compreensão da dimensão de ancestralidade para o candomblé..

Palavras Chave: Candomblé Angola, Banto, Etnomusicologia, Transmissão Oral

\section{Referências}

\section{Revisão de Referências Bibliográficas}

\section{Sobre Candomblé Angola}

AMARAL, Rita \& GONÇALVES DA SILVA, Vagner. Cantar para subir: um estudo antropológico da música ritual no candomblé paulista. Religião e Sociedade, n. 16 (1/2), Rio de Janeiro: ISER, 1992.

BARCELLOS, Mario Cesar. Jamberesu: as cantigas de angola. Rio de Janeiro: Pallas, 1998.

CAPONE, Stefania. "A dança dos deuses: uma análise da dança de possessão no candomblé Angola Kassanje”. Dissertação de mestrado. Rio de Janeiro: PPGAS/Museu Nacional/UFRJ, 1991.

CARNEIRO, Édison. Religiões negras, Negros bantos. Rio de Janeiro: Civilização Brasileira, 1991. Candomblés da Bahia. Rio de Janeiro: Civilização Brasileira, 1986.

LOPES, Nei. Bantos, malês e identidade negra. $3^{\text {a }}$ edição. Belo Horizonte: Autêntica Editora, 2011.

PRANDI, Reginaldo. "Linhagem e legitimidade no candomblé paulista", Revista Brasileira de Ciências Sociais, n.14, p.18-31, 1990. PUBLICAÇÃO 1990

PUBICAÇÃO 1991

Os candomblés de São Paulo. São Paulo: HUCITEC/EDUSP, 1991.

SERRA, Ordep Trindade. "Na trilha das crianças: os erês num terreiro angola". Dissertação de mestrado. Brasília: UFB, 1978.

COSTA, José Rodrigues da. Candomblé de Angola: Nação Kassanje. História, etnia, inkises, dialeto litúrgico dos Kassanjes. $3^{\text {a }}$ edição. Rio de Janeiro: 1996. 


\section{Referências Bibliográficas}

Sobre Religiões, candomblés e África

APPIAH, Kwame Anthony. Na casa de meu pai: a África na filosofia da cultura. Tradução Vera Ribeiro. Rio de Janeiro: Contraponto, 1997.

BASTIDE, Roger. O candomblé da Bahia: rito nagô. São Paulo: Companhia das Letras, 2011.

As religiões africanas no Brasil. Contribuição a uma sociologia das interpenetrações de civilizações. São Paulo: Livraria Pioneira Editora, 1971.

. As Américas negras: as civilizações africanas no Novo Mundo. São Paulo: DIFEL/EDUSP, 1974.

Estudos afro-brasileiros. São Paulo: Perspectiva, 1973.

BRAGA, Júlio. A cadeira de ogã. Rio de Janeiro: Pallas, 2009.

CAPONE, Stefania. A busca da África no candomblé: tradição e poder no Brasil. Rio de Janeiro: Pallas, 2004

CARNEIRO, Édison. Candomblés da Bahia. Rio de Janeiro: Civilização Brasileira, 1986.

CARVALHO, José Jorge de. “A força da nostalgia: a concepção do tempo histórico dos cultos afrobrasileiros tradicionais”, Religião e Sociedade, n.14 (2), p. 36-61, 1987.

Anuário Antropológico 90, Rio de Janeiro: Tempo Brasileiro, p. 91-107, 1993.

CASTRO, Yeda Pessoa de. "Língua e nação de candomblé”, África, n.4, São Paulo, p.57-77, 1981.

COSTA LIMA, Vivaldo da. "O conceito de 'nação' nos candomblés da Bahia”, AfroÁsia, n.12, p. 65-90, 1976.

"Nações-de-candomblé". Em: COSTA LIMA, Vivaldo da (org.). Encontro de nações-de-candomblé. Salvador: Ianamá/CEAO/CED, p. 11-26 (Estudos Documentos, 10), 1984.

DANTAS, Beatriz Góis. Vovó nagô e papai branco: Usos e abusos da África no Brasil. Rio de janeiro: Graal, 1988.

EVANS-PRITCHARD, Edward Evan. "A religião e os antropólogos”, Religião e Sociedade, n.13 (1), p.4-19, 1986.

ESTUDOS AFRO-BRASILEIROS. Trabalhos apresentados ao I Congresso afro-brasileiro, Recife, 1934. Recife: Fundação Joaquim Nabuco/Editora Massangana, 2 vols.

GONÇALVES DA SILVA, Vagner. "O candomblé na cidade: tradição e renovação”. Dissertação de mestrado. São Paulo: EFLCH/USP, 1992. 
HAMPATÊ BA, Amadou. A tradição viva. In: KI-ZERBO, J. História Geral da África I. Brasília: UNESCO, p. 167-212, 2010.

LANDES, RUTH. A cidade das mulheres. Rio de Janeiro: Civilização Brasileira, 1967.

LEITE, Fábio Rubens da Rocha. Tradições e práticas religiosas negro-africanas na região de São Paulo. In: Culturas Africanas (Documento da Reunião de Peritos sobre "As sobrevivências das tradições religiosas africanas nas Caraíbas e na América Latina”. São Luis do Maranhão, 1985) São Luis, UNESCO, 1986.

A questão ancestral: notas sobre ancestrais $e$ instituições ancestrais em sociedades africanas: Ioruba, Agni e Senufo. Tese de doutorado apresentada no Departamento de Ciências Sociais da Faculdade de Filosofia, Letras e Ciências Humanas da USP: 1982.

LOPES, Nei. Bantos, malês e identidade negra. $3^{\text {a }}$ edição. Belo Horizonte: Autêntica Editora, 2011.

MUKUNA, Kasadi wa. Contribuição Bantu na música popular brasileira: perspectivas etnomusicológicas. São Paulo: Terceira Margem, 2006.

ORTIZ, Renato. A morte branca do feiticeiro negro: umbanda e sociedade brasileira. São Paulo: Brasiliense, 1988.

PRANDI, Reginaldo \& GONÇALVES, Vagner. “Axé São Paulo: notas preliminares de pesquisa sobre as origens e mudanças do candomblé na região metropolitana de São Paulo”. Em: MOURA, Carlos Eugênio Marcondes (org.). Meu sinal está no teu corpo, P. 220-39. 1989.

SANTOS, Juana Elbein dos. Os Nagô e a morte. Petrópolis: Vozes, 1977.

"Pierre Verger e os resíduos coloniais: o 'outro'

fragmentado, Religiões e Sociedade, n.8, 1982. 